\title{
Functional isocoumarin-containing polymers synthesized by rhodium-catalyzed oxidative polycoupling of aryl diacid and internal diyne $\uparrow$
}

\author{
Ting Han, ${ }^{a, b}$ Haiqin Deng, ${ }^{a, b}$ Chris Y. Y. Yu, ${ }^{a, b}$ Chen Gui, ${ }^{a, b}$ Zhegang Song, ${ }^{a, b}$ \\ Ryan T. K. Kwok, ${ }^{a, b}$ Jacky W. Y. Lam*a,b and Ben Zhong Tang*a,b,c
}

\begin{abstract}
An atom-economical and straightforward polymerization method to generate functional isocoumarincontaining polymers was developed in this work. The oxidative polycoupling of 4,4'-(1,2-diphenyl-1,2ethenylene)dibenzoic acid and 1,6-bis[4-(phenylethynyl)phenoxy]hexane proceeds efficiently in dimethylformamide under nitrogen or air in the presence of $\left[\mathrm{Cp}^{*} \mathrm{RhCl}_{2}\right]_{2}$ and a catalytic amount of $\mathrm{Cu}(\mathrm{OAc})_{2} \cdot \mathrm{H}_{2} \mathrm{O}$ at $120{ }^{\circ} \mathrm{C}$ for $24 \mathrm{~h}$, generating a polymer with a high molecular weight of up to 42900 in a high yield of up to $92.9 \%$. An isocoumarin framework forms in situ during the polymerization from readily accessible and inexpensive monomers. The resulting polymer possesses good thermal stability, optical transparency and film-forming ability. Its thin film exhibits high and UV-tunable refractive indices $(n=$ 1.9697-1.6507) in a wide wavelength region of 390-890 nm. A two-dimensional fluorescent photopattern can be readily fabricated by irradiating its thin film under UV light through a copper mask. Due to the incorporation of tetraphenylethene units in the monomer, the polymer obtained is weakly emissive in solution but it emits intensely when aggregated, demonstrating a phenomenon of aggregation-induced emission.
\end{abstract}

\author{
Received 3rd February 2016 \\ Accepted 25th February 2016 \\ DOI: 10.1039/c6py00206d \\ www.rsc.org/polymers
}

\section{Introduction}

The exploration of novel functional polymeric materials and the development of their synthetic routes have always been enduring research topics in polymer science. ${ }^{1}$ As a group of new advanced materials, polymers with fused-heterocyclic units in the main chains have attracted considerable attention. In the past few decades, a series of fused-heterocyclic polymers, for example, polymers containing benzodipyrrole, ${ }^{2}$ benzofuran, ${ }^{3}$ benzothiophene, ${ }^{4}$ benzothiadiazole,${ }^{5}$ benzylcarb-

\footnotetext{
${ }^{a}$ HKUST-Shenzhen Research Institute, No. 9 Yuexing 1st RD, South Area, Hi-tech Park, Nanshan, Shenzhen 518057, China.E-mail: chjacky@ust.hk, tangbenz@ust.hk ${ }^{b}$ Department of Chemistry, Hong Kong Branch of Chinese National Engineering Research Center for Tissue Restoration and Reconstruction, Institute for Advanced Study, Institute of Molecular Functional Materials, Division of Biomedical Engineering, Division of Life Science and State Key Laboratory of Molecular Neuroscience, The Hong Kong University of Science \& Technology, Clear Water Bay, Kowloon, Hong Kong, China

${ }^{c}$ Guangdong Innovative Research Team, SCUT-HKUST Joint Research Laboratory, State Key Laboratory of Luminescent Materials and Devices, South China University of Technology, Guangzhou 510640, China

$\dagger$ Electronic supplementary information (ESI) available: Solvent effect on the polymerization of $\mathbf{1}$ and $2,{ }^{1} \mathrm{H}$ NMR spectrum, ${ }^{13} \mathrm{C}$ NMR spectrum and HRMS spectrum of model compound $\mathbf{3} \mathbf{b}$, ORTEP drawing and crystal data for single crystals of $\mathbf{3 b}$, TGA and DSC thermograms of P1/2, size distributions of nanoparticles of $\mathbf{P} \mathbf{1} / \mathbf{2}$ in THF/water mixtures, refractive indices and chromatic dispersions of P1/2. CCDC 1043916. For ESI and crystallographic data in CIF or other electronic format see DOI: 10.1039/c6py00206d
}

azole, ${ }^{6}$ and naphthopyran, ${ }^{7}$ have been developed and investigated. Owing to their structural advantages of both the high conjugation of fused rings and the distinctive electrical and photophysical properties of heterocyclic moieties, they have found a variety of applications as external stimuli-responsive materials,${ }^{8}$ fluorescent sensors ${ }^{9}$ and photoelectronic devices, such as polymer solar cells, ${ }^{10}$ polymer field-effect transistors, ${ }^{11}$ polymer light-emitting diodes, ${ }^{6}$ etc. By introducing appropriate substituents, plentiful polymeric structures with novel properties and functionalities could be achieved. However, the syntheses of multisubstituted fused-heterocyclic polymers normally require limited and expensive fused aromatic substrates, complicated synthetic routes, elaborate reaction control and painful isolation, which significantly restrict their accessibility. Therefore, it is in great demand to develop facile and efficient synthetic methods to generate multifunctional polymers with fused-heterocyclic units.

Isocoumarins are an important class of heterocyclic compounds, in the structure of which a lactone ring is fused to a benzene ring. Isocoumarin exists as the nucleus in many natural products with a variety of interesting biological activities. ${ }^{12}$ As such, great endeavors have been made to prepare isocoumarin derivatives via expedient synthetic strategies. ${ }^{13}$ However, to the best of our knowledge, the development of polymerization routes to polymers with isocoumarin frameworks in the main chains has rarely been reported. Our group is interested in the exploration of new polymerization methods 
to construct functional polymers based on triple-bond reactions. Recently, we noticed a direct oxidative coupling of benzoic acids with internal alkynes reported by Ueura et al. (Scheme 1). ${ }^{14}$ This reaction proceeded smoothly in the presence of $\left[\mathrm{Cp}^{*} \mathrm{RhCl}_{2}\right]_{2}$ and $\mathrm{Cu}(\mathrm{OAc})_{2} \cdot \mathrm{H}_{2} \mathrm{O}$, producing the corresponding isocoumarin derivatives in good to excellent yields. The amount of copper salt used could be reduced to a catalytic quantity when the reaction was conducted in air. Except water, no waste was formed in this reaction, which was indicative of its high atom-economical character.

In this work, we successfully developed this organic alkyne reaction into an efficient polymerization tool for the synthesis of isocoumarin-containing polymers with advanced functionalities. Unlike some polymerization methods, which require skill-demanding techniques, the present polymerization route is much simpler and easier to operate. The oxidative polycoupling of 4,4'-(1,2-diphenyl-1,2-ethenylene)dibenzoic acid (1) and 1,6-bis[4-(phenylethynyl)phenoxy]hexane (2) proceeds efficiently in dimethylformamide (DMF) under nitrogen or air in the presence of $\left[\mathrm{Cp}^{*} \mathrm{RhCl}_{2}\right]_{2}$ and a catalytic amount of $\mathrm{Cu}(\mathrm{OAc})_{2} \cdot \mathrm{H}_{2} \mathrm{O}$ at $120{ }^{\circ} \mathrm{C}$ for $24 \mathrm{~h}$, generating a polymer with a high molecular weight ( $M_{\mathrm{w}}$ up to 42900 ) in a high yield (up to 92.9\%) (Scheme 2). Model compounds are designed and synthesized to assist the structural characterization of the polymer obtained. It is worthy to note that the isocoumarin unit forms in the polymer in situ during this polymerization from inexpensive and readily available starting materials. The resulting polymer possesses good thermal stability, filmforming ability and excellent optical transparency. In addition, it shows a photophysical phenomenon of aggregation-induced emission (AIE) due to the incorporation of tetraphenylethene (TPE) units in the polymer backbone. The thin film of the polymer exhibits high and tunable refractive indices. Owing to its sensitivity to UV irradiation, the polymer can be used for generating a fluorescent photopattern with good resolution by the photolithography process.

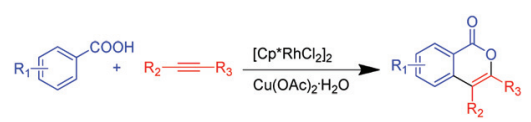

Scheme 1 Alkyne-based oxidative coupling reaction.

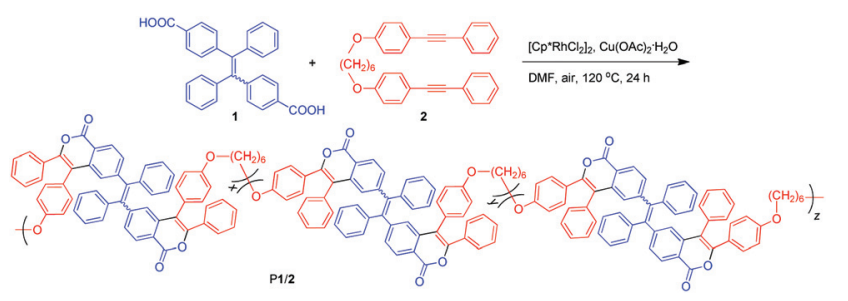

Scheme 2 Synthetic route to isocoumarin-containing polymers by rhodium-catalyzed oxidative polycoupling of aryl diacid and internal diyne.

\section{Results and discussion}

\section{Polymerization}

In order to develop the rhodium-catalyzed waste-free oxidative coupling into an efficient polymerization methodology for the construction of isocoumarin-containing polymers, difunctional monomers $\mathbf{1}$ and $\mathbf{2}$ were designed and synthesized according to our previous publication. ${ }^{15}$

We first tried to polymerize 1 and 2 in $o$-xylene under nitrogen at $120^{\circ} \mathrm{C}$. As depicted in Table 1 , when the polymerization was carried out at a monomer concentration of $0.10 \mathrm{M}$ in the presence of $\left[\mathrm{Cp}^{*} \mathrm{RhCl}_{2}\right]_{2} \quad(0.08$ equiv. $)$ and $\mathrm{Cu}(\mathrm{OAc})_{2} \cdot \mathrm{H}_{2} \mathrm{O}$ ( 2 equiv.), an insoluble gel was observed, indicating that the polymerization did occur and proceeded very fast. We then decreased the monomer concentration to $0.05 \mathrm{M}$, while keeping the monomer concentration to that of the catalyst at a ratio of $1: 1: 0.08: 2=[1] /[2] /[\mathrm{Rh}] /[\mathrm{Cu}]$. Delightfully, a polymer with a high molecular weight $\left(M_{\mathrm{w}}=42900\right)$ was obtained in a good yield (79.5\%). However, the use of a large amount of $\mathrm{Cu}(\mathrm{OAc})_{2} \cdot \mathrm{H}_{2} \mathrm{O}$ as an oxidant created some problems. The remaining copper salt was hard to be removed from the reaction mixture, which had complicated the purification process and led to the loss of product yield. On the other hand, the presence of copper salt in the polymer was harmful for its material properties, especially the light emission. To optimize the conditions for the polymerization, we thus reduced the amount of $\mathrm{Cu}(\mathrm{OAc})_{2} \cdot \mathrm{H}_{2} \mathrm{O}$ from 2 equivalents to 1 equivalent, but doing so, only a trace amount of the polymeric product was obtained. According to the plausible mechanism, ${ }^{14}$ the $\mathrm{Cu}(\mathrm{I})$ species formed during the reaction can be reoxidized to $\mathrm{Cu}(\mathrm{II})$ under air. Inspired by this, we envisioned that it might be possible to reduce the amount of $\mathrm{Cu}(\mathrm{OAc})_{2} \cdot \mathrm{H}_{2} \mathrm{O}$ used if the polymerization reaction was carried out in air instead of under nitrogen. Therefore, we tried to conduct the polymerization of 1 and 2 in $\mathrm{DMF}$ in air at $120^{\circ} \mathrm{C}$ for $24 \mathrm{~h}$ in the presence of merely a catalytic amount of $\mathrm{Cu}(\mathrm{OAc})_{2} \cdot \mathrm{H}_{2} \mathrm{O}$. Interestingly, the polymerization proceeded efficiently, which afforded a polymer with a $M_{\mathrm{w}}$ of 25900 in a high yield (85.2\%). The improved polymerization conditions not only avoid the use of a stoichiometric amount of $\mathrm{Cu}(\mathrm{OAc})_{2} \cdot \mathrm{H}_{2} \mathrm{O}$, making the polymerization more economical and environmentally friendly, but also simplify the experimental procedure, such as skipping the step for evac-

Table 1 Polymerization of 1 and $2^{a}$

\begin{tabular}{llllllll}
\hline Entry & {$[1](\mathrm{M})$} & {$[2](\mathrm{M})$} & {$[\mathrm{Rh}](\mathrm{M})$} & {$[\mathrm{Cu}](\mathrm{M})$} & Yield $(\%)$ & $M_{\mathrm{w}}{ }^{b}$ & $M_{\mathrm{w}} / M_{\mathrm{n}}{ }^{b}$ \\
\hline 1 & 0.10 & 0.10 & 0.008 & 0.20 & Gel & & \\
2 & 0.05 & 0.05 & 0.004 & 0.10 & 79.5 & 42900 & 3.99 \\
3 & 0.05 & 0.05 & 0.004 & 0.05 & Trace & & \\
4 & 0.10 & 0.10 & 0.002 & 0.01 & 85.2 & 25900 & 2.40
\end{tabular}

${ }^{a}$ Carried out in $o$-xylene under nitrogen (entries $1-3$ ) or in DMF in air (entry 4) at $120{ }^{\circ} \mathrm{C}$ for $24 \mathrm{~h}$ in the presence of $\left[\mathrm{Cp}^{*} \mathrm{RhCl}_{2}\right]_{2}$ and $\mathrm{Cu}(\mathrm{OAc})_{2} \cdot \mathrm{H}_{2} \mathrm{O} .{ }^{b}$ Determined by GPC in THF on the basis of a linear polystyrene calibration. 
uating the Schlenk tube under vacuum and flushing it with dry nitrogen for several times.

Based on the above mentioned advantages, we thus utilized the aerobic conditions for further condition optimization. We then shifted our investigation on the effect of catalyst loading on the polymerization. As shown in Table 2, the molecular weight of the resulting polymer was enhanced from 16000 to 25900 when the catalyst concentration was gradually decreased from $0.008 \mathrm{M}$ to $0.002 \mathrm{M}$. Therefore, $0.002 \mathrm{M}$ was chosen to be the optimal catalyst concentration for the subsequent study.

Encouraged by the preliminary results shown in Table 1, entry 4 , we then gained insight into the effect of oxidant concentration on the polymerization. From the results depicted in Table 3, it is noticed that while the isolated yield seemed to be insensitive to the amount of $\mathrm{Cu}(\mathrm{OAc})_{2} \cdot \mathrm{H}_{2} \mathrm{O}$ used, the molecular weight of the polymer obtained increased gradually when a lower oxidant concentration was used for the polymerization. The best results $\left(M_{\mathrm{w}}=26300\right.$; yield $\left.=88.1 \%\right)$ were acquired at an oxidant concentration of $0.005 \mathrm{M}$. It is noteworthy that only a trace amount of the polymeric product was obtained in the absence of $\mathrm{Cu}(\mathrm{OAc})_{2} \cdot \mathrm{H}_{2} \mathrm{O}$, which is indicative of its crucial role in the polymerization. The solvent effect on the polymerization of 1 and 2 was also examined (Table S1 $\uparrow$ ). The results indicated that DMF was the solvent of choice among the tested solvents. The polycoupling proceeded deficiently in DMSO, $o$-DCB, and $o$-xylene, giving only a trace amount of polymeric products.

Table 4 shows the effect of monomer concentration on the polymerization. Taking both the isolation yield and molecular weight of the resulting polymer into consideration, a

Table 2 Effect of catalyst loading on the polymerization of 1 and $2^{a}$

\begin{tabular}{lllll}
\hline Entry & {$[\mathrm{Rh}](\mathrm{M})$} & Yield $(\%)$ & $M_{\mathrm{w}}{ }^{b}$ & $M_{\mathrm{w}} / M_{\mathrm{n}}{ }^{b}$ \\
\hline $1^{c}$ & 0.002 & 85.2 & 25900 & 2.40 \\
2 & 0.004 & 92.9 & 18200 & 2.73 \\
3 & 0.006 & 91.8 & 16900 & 2.49 \\
4 & 0.008 & 90.0 & 16000 & 2.39
\end{tabular}

${ }^{a}$ Carried out in DMF in air at $120{ }^{\circ} \mathrm{C}$ for $24 \mathrm{~h}$ in the presence of $\left[\mathrm{Cp}^{*} \mathrm{RhCl}_{2}\right]_{2}$ and $\mathrm{Cu}(\mathrm{OAc})_{2} \cdot \mathrm{H}_{2} \mathrm{O} .[1]=0.10 \mathrm{M},[2]=0.10 \mathrm{M},[\mathrm{Cu}]=0.01$ M. ${ }^{b}$ Determined by GPC in THF on the basis of a linear polystyrene calibration. ${ }^{c}$ Data taken from Table 1 , entry 4.

Table 3 Effect of oxidant concentration on the polymerization of 1 and $2^{a}$

\begin{tabular}{lllll}
\hline Entry & {$[\mathrm{Cu}](\mathrm{M})$} & Yield $(\%)$ & $M_{\mathrm{W}}{ }^{b}$ & $M_{\mathrm{w}} / M_{\mathrm{n}}{ }^{b}$ \\
\hline 1 & 0 & Trace & & \\
2 & 0.005 & 88.1 & 26300 & 2.95 \\
$3^{c}$ & 0.010 & 85.2 & 25900 & 2.40 \\
4 & 0.015 & 86.2 & 10000 & 2.05
\end{tabular}

${ }^{a}$ Carried out in DMF in air at $120{ }^{\circ} \mathrm{C}$ for $24 \mathrm{~h}$ in the presence of $\left[\mathrm{Cp}^{*} \mathrm{RhCl}_{2}\right]_{2}$ and $\mathrm{Cu}(\mathrm{OAc})_{2} \cdot \mathrm{H}_{2} \mathrm{O}$. [1] $=0.10 \mathrm{M},[2]=0.10 \mathrm{M},[\mathrm{Rh}]=$ $0.002 \mathrm{M} .{ }^{b}$ Determined by GPC in THF on the basis of a linear polystyrene calibration. ${ }^{c}$ Data taken from Table 1 , entry 4.
Table 4 Effect of monomer concentration on the polymerization of 1 and $2^{a}$

\begin{tabular}{llllll}
\hline Entry & {$[1](\mathrm{M})$} & {$[2](\mathrm{M})$} & Yield $(\%)$ & $M_{\mathrm{W}}{ }^{b}$ & $M_{\mathrm{w}} / M_{\mathrm{n}}{ }^{b}$ \\
\hline 1 & 0.05 & 0.05 & Trace & & \\
$2^{c}$ & 0.10 & 0.10 & 88.1 & 26300 & 2.95 \\
3 & 0.20 & 0.20 & 74.9 & 27400 & 2.71 \\
4 & 0.30 & 0.30 & Gel & &
\end{tabular}

${ }^{a}$ Carried out in DMF in air at $120{ }^{\circ} \mathrm{C}$ for $24 \mathrm{~h}$ in the presence of $\left[\mathrm{Cp}^{*} \mathrm{RhCl}_{2}\right]_{2}$ and $\mathrm{Cu}(\mathrm{OAc})_{2} \cdot \mathrm{H}_{2} \mathrm{O} .[\mathrm{Rh}]=0.002 \mathrm{M},[\mathrm{Cu}]=0.005 \mathrm{M}$. ${ }^{b}$ Determined by GPC in THF on the basis of a linear polystyrene calibration. ${ }^{c}$ Data taken from Table 3, entry 2.

monomer concentration of $0.10 \mathrm{M}$ was found to be the preferred polymerization condition. When the concentration was too high or too low, poorer polymerization results were obtained. For example, while a trace amount of the polymeric product was isolated at a monomer concentration of $0.05 \mathrm{M}$, doubling the concentration led to an obvious decrease in the product yield. Further raising the concentration resulted in the formation of an insoluble gel (Table 4, entry 4). These results suggest that a precise control on the monomer concentration is of great importance for the smooth occurrence of the polymerization.

We finally followed the time course on the polymerization and the results are given in Table 5. The polymerization of 1 and 2 was so efficient that a polymer with a $M_{\mathrm{w}}$ value of 20500 was furnished in a high yield (82.4\%) after $6 \mathrm{~h}$. The molecular weight was gradually enhanced by prolonging the reaction time and it reached a maximum value of 26300 at $24 \mathrm{~h}$, while the reaction yield remained almost unchanged after $12 \mathrm{~h}$.

\section{Structural characterization}

To verify that the polycoupling reaction occurs both under nitrogen and in air, and to gain insight into the structure of the polymer, we designed and synthesized model compounds 3 and $\mathbf{4}$ according to the reaction routes shown in scheme 3. By the dehydrogenative coupling of a commercially available p-toluic acid 5 and an asymmetric internal alkyne 6 under nitrogen in $o$-xylene at $120{ }^{\circ} \mathrm{C}$, a model compound 3 with two isomeric structures was prepared. One of the isomers (3b) was separated by column chromatography and characterized by standard spectroscopic methods (Fig. S1-S3†). Single crystals

Table 5 Time course on the polymerization of 1 and $2^{a}$

\begin{tabular}{lllll}
\hline Entry & Time (h) & Yield (\%) & $M_{\mathrm{w}}{ }^{b}$ & $M_{\mathrm{w}} / M_{\mathrm{n}}{ }^{b}$ \\
\hline 1 & 6 & 82.4 & 20500 & 2.97 \\
2 & 12 & 88.7 & 21900 & 3.09 \\
3 & 18 & 88.2 & 23900 & 3.26 \\
$4^{c}$ & 24 & 88.1 & 26300 & 2.95
\end{tabular}

${ }^{a}$ Carried out in DMF in air at $120{ }^{\circ} \mathrm{C}$ for $24 \mathrm{~h}$ in the presence of $\left[\mathrm{Cp}^{*} \mathrm{RhCl}_{2}\right]_{2}$ and $\mathrm{Cu}(\mathrm{OAc})_{2} \cdot \mathrm{H}_{2} \mathrm{O} .[1]=0.10 \mathrm{M},[2]=0.10 \mathrm{M},[\mathrm{Rh}]=0.002$ $\mathrm{M},[\mathrm{Cu}]=0.005 \mathrm{M} .{ }^{b}$ Determined by GPC in THF on the basis of a linear polystyrene calibration. ${ }^{c}$ Data taken from Table 3 , entry 2. 


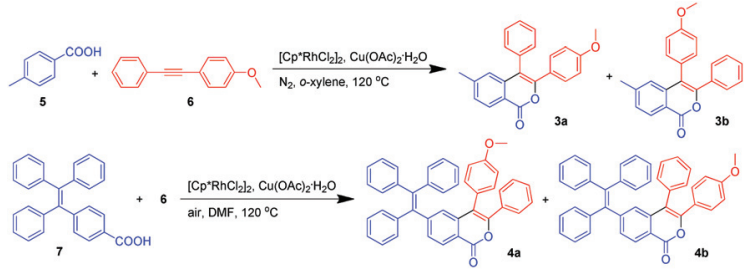

Scheme 3 Synthetic routes to model compounds 3 and 4 .

of $\mathbf{3 b}$ were obtained from slow evaporation of its dichloromethane/hexane mixture, whose structure was confirmed by $\mathrm{X}$-ray diffraction analysis. Its ORTEP drawing is given in Fig. $\mathrm{S} 4 \uparrow$ and the corresponding crystal data are summarized in Table S2. $\dagger$ In order to support precise structural characterization, we prepared other model compounds $\mathbf{4 a}$ and $\mathbf{4 b}$ in air in DMF at $120{ }^{\circ} \mathrm{C}$ using 6 and TPE-containing monocarboxylic acid 7 as starting materials. The detailed descriptions of the synthetic approach and characterization of the model compounds are provided in the Experimental section. All the monomers, model compounds and the polymer were fully characterized by IR and NMR spectroscopies.

Fig. 1 shows the IR spectra of monomers 1 and 2, model compounds $\mathbf{3}$ and $\mathbf{4}$ and polymer P1/2. A broad absorption band spreading from $3600 \mathrm{~cm}^{-1}$ to $2600 \mathrm{~cm}^{-1}$ is observed in the spectrum of 1 due to the $\mathrm{O}-\mathrm{H}$ stretching vibrations of its carboxyl groups. In a similar absorption region, the spectra of 3, 4 and P1/2, however, display only sharp peaks resulting from the $\mathrm{C}-\mathrm{H}$ stretching vibrations at about $3040 \mathrm{~cm}^{-1}$ and $2900 \mathrm{~cm}^{-1}$. On the other hand, the characteristic peak of the $\mathrm{C} \equiv \mathrm{C}$ stretching vibration at $2218 \mathrm{~cm}^{-1}$ of 2 disappears after the model reaction or the polymerization. These results suggest that the carboxyl groups of $\mathbf{1}$ and triple bonds of $\mathbf{2}$

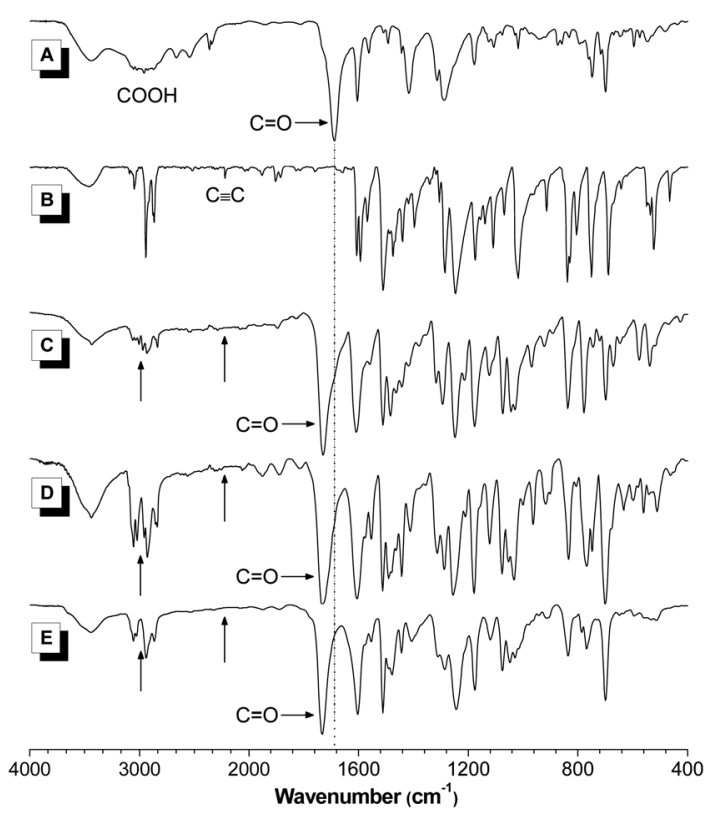

Fig. 1 IR spectra of (A) 1, (B) 2, (C) 3, (D) 4, and (E) P1/2. have been transformed into isocoumarin rings in $\mathbf{P} \mathbf{1} \mathbf{2}$ by the oxidative coupling or polycoupling reaction. In addition, compared with monomer 1 , the intense $\mathrm{C}=\mathrm{O}$ stretching band shifts from $1687 \mathrm{~cm}^{-1}$ to near $1730 \mathrm{~cm}^{-1}$ in the spectra of two model compounds and the corresponding polymer, which further reveals the occurrence of the polymerization.

Fig. 2 depicts the ${ }^{1} \mathrm{H}$ NMR spectra of the polymer and its monomers as well as the model compounds 3 and 4 . The absorption peak at $\delta 12.90$ in the spectrum of $\mathbf{1}$ is assigned to the characteristic resonances of the carboxylic acid protons, which disappears in the spectra of the model compounds and the polymer. The resonances of the phenyl protons adjacent to the carboxyl groups in $\mathbf{1}$ at $\delta 7.72$ also shift to 8.09 after the polymerization. These observations confirm the complete consumption of the carboxyl groups of $\mathbf{1}$ by the polymerization and suggest the formation of isocoumarin units. The corresponding absorption of the protons next to the oxygen atom at $\sim \delta 4.00$ in 2 now appears as two different signals in the spectra of 3, 4 and P1/2 owing to the presence of regio-isomeric units in their structures. By comparison with the ${ }^{1} \mathrm{H}$ NMR spectrum of $3 \mathbf{b}$ (Fig. S1 $\dagger$ ), we can readily assign the peaks at $\delta 3.84$ and 3.75 to the resonances of the methoxy protons in $\mathbf{3 b}$ and $\mathbf{3 a}$, respectively.

Fig. 3 shows the ${ }^{13} \mathrm{C}$ NMR spectrum of $\mathrm{P} \mathbf{1} / \mathbf{2}$ in dichloromethane- $d_{2}$. The polymer exhibits no resonance peaks of internal acetylene carbon atoms of 2 at $\delta 89.47$ and 88.03. On the other hand, the resonances of the carbonyl carbon of 1 shift from $\delta 167.02$ to 162.16 after the polymerization. The phenyl carbon attached to the oxygen atom absorbs at different chemical shifts in the spectra of $\mathbf{3 , 4}$ and P1/2 due to their isomeric nature. The IR and NMR spectra of P1/2

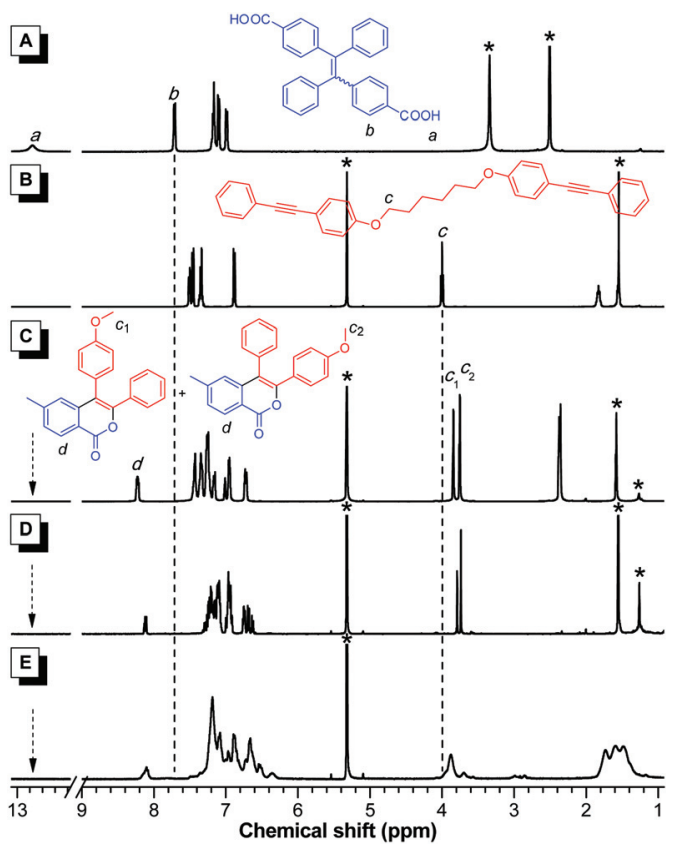

Fig. $2{ }^{1} \mathrm{H}$ NMR spectra of (A) 1 in DMSO- $d_{6}$ and (B) 2, (C) 3, (D) 4 and (E) $\mathrm{P} 1 / 2$ in dichloromethane- $d_{2}$. 


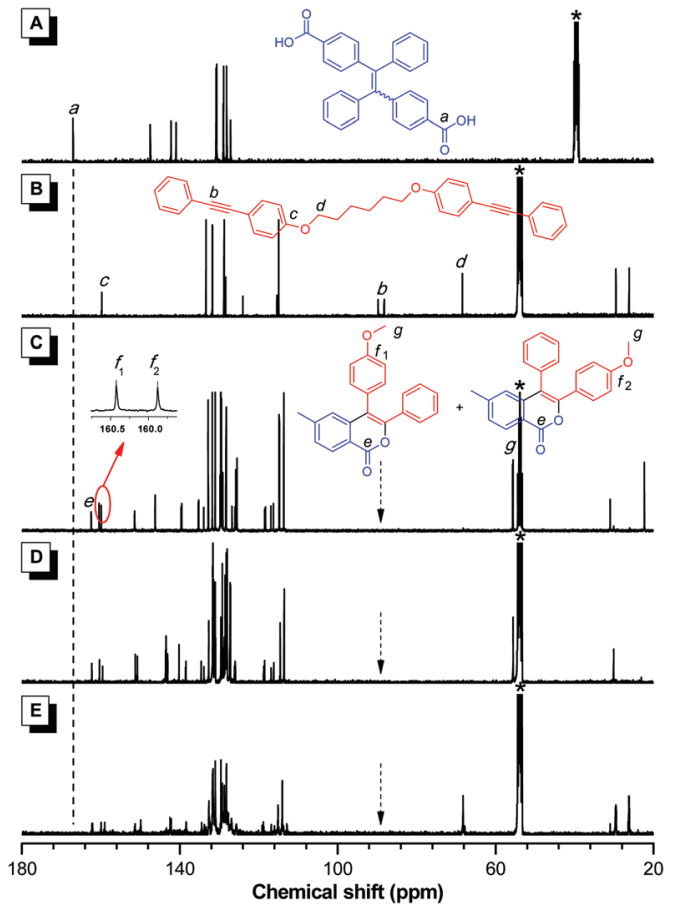

Fig. $3{ }^{13} \mathrm{C}$ NMR spectra of (A) 1 in DMSO- $d_{6}$ and (B) 2, (C) 3, (D) 4 and (E) $\mathrm{P} 1 / 2$ in dichloromethane- $d_{2}$.

resemble largely those of model compounds. All these characterization results demonstrate that we have indeed obtained the polymer with a structure containing isomeric conformations as shown in Scheme 2.

\section{Solubility and thermal stability}

$\mathrm{P} 1 / 2$ can readily dissolve in common organic solvents, such as tetrahydrofuran (THF), dichloromethane, chloroform and 1,4dioxane, thanks to both its twisted TPE moieties and flexible alkyl chains. Besides, as evaluated by thermogravimetric analysis (TGA), P1/2 is thermally stable. It loses $5 \%$ of its weight at a temperature of $280{ }^{\circ} \mathrm{C}$, while a $10 \%$ weight loss occurs at $415{ }^{\circ} \mathrm{C}$ (Fig. S5 $\dagger$ ). The good resistance of P1/2 to thermolysis may stem from its high aromatic content in the polymer structure. The differential scanning calorimetry (DSC) measurement reveals that the glass transition temperature $\left(T_{\mathrm{g}}\right)$ of $\mathbf{P 1} / \mathbf{2}$ is as high as $208{ }^{\circ} \mathrm{C}$, indicative of its high morphological stability (Fig. S6†).

\section{Optical properties}

As shown in Fig. 4, the UV spectra of the model compounds (3 and 4) and the polymer (P1/2) in THF solutions are peaked at a similar wavelength $(\sim 310 \mathrm{~nm})$, but the onset wavelength readily shifts to the longer wavelength region with an increase in the electronic conjugation from $\mathbf{3}$ to $\mathbf{4}$ and then P1/2. It is noteworthy that $\mathbf{P} \mathbf{1} / \mathbf{2}$ exhibits excellent optical transparency. It mainly absorbs light in the UV region, showing almost no absorption in the visible region. Although it possesses aromatic rings, the presence of ester groups and hexyl chains

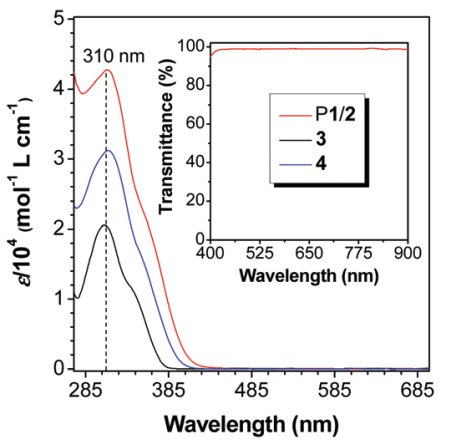

Fig. 4 Absorption spectra of 3, 4 and P1/2 in THF solutions. Solution concentration: $10 \mu \mathrm{M}$. Inset: transmission spectrum of P1/2 in THF solution at wavelengths from 400 to $900 \mathrm{~nm}$.

between these electronically unsaturated units has weakened their electronic communications and hence the electronic conjugation. Such a high optical clarity makes P1/2 a promising candidate material for photonic applications. ${ }^{16}$

TPE is a well-known AIE-active luminogen. ${ }^{17}$ Due to the presence of TPE units in the molecular structure, both 4 and $\mathrm{P} 1 / 2$ are expected to be AIE-active. In order to confirm this, their photoluminescence (PL) in THF and THF/water mixtures with different water fractions $\left(f_{\mathrm{w}}\right)$ is investigated (Fig. 5). In pure THF and THF/water mixtures with $f_{\mathrm{w}}$ lower than $80 \mathrm{vol} \%$, the PL spectra of $\mathbf{4}$ are basically flat lines parallel to the
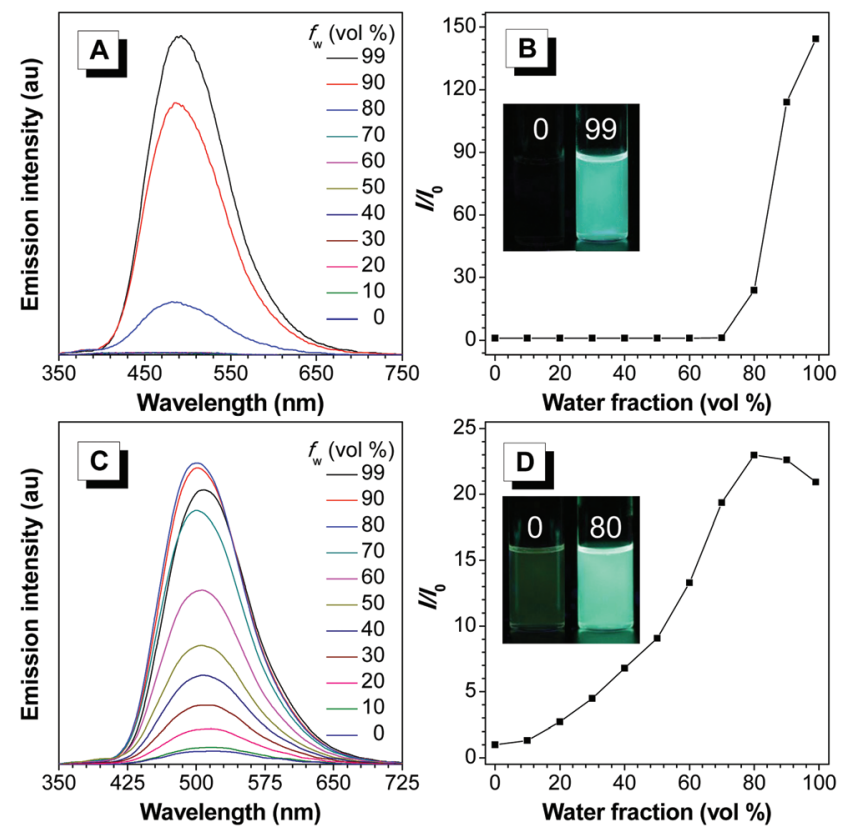

Fig. 5 PL spectra of (A) 4 and (C) P1/2 in THF and THF/water mixtures with different water fractions $\left(f_{\mathrm{w}}\right)$. (B and $\left.\mathrm{D}\right)$ Plots of relative $\mathrm{PL}$ intensity $\left(I / I_{0}\right)$ versus the composition of the aqueous mixtures of 4 and $\mathrm{P} 1 / 2 . I_{0}=$ intensity at $f_{\mathrm{w}}=0 \%$. Inset: fluorescence photographs of (B) 4 in THF/ water mixtures with a $f_{\mathrm{w}}$ of $0 \%$ and $99 \%$ and (D) P1/2 in THF/water mixtures with a $f_{\mathrm{w}}$ of $0 \%$ and $80 \%$ taken under $365 \mathrm{~nm}$ UV irradiation. Solution concentration: $10 \mu \mathrm{M}$; excitation wavelength: $311 \mathrm{~nm}$. 
abscissa. This indicates that the dye molecule is almost nonemissive under such circumstances. However, when a large amount of water is added, the emission starts to become stronger progressively. From pure THF solution to 99\% aqueous mixture, the PL intensity is increased by 144 -fold. This result suggests the typical AIE feature of 4 . Polymer P1/2 also displays a similar emission behavior. The faint emission of its THF solution is swiftly enhanced upon addition of water. The higher the water content, the stronger is the PL intensity. Compared with 4 , the PL of P1/2 is more sensitive to the change in the solvent environment, which may origin from its more hydrophobic nature and thus its ease to form aggregates in an aqueous mixture with low $f_{\mathrm{w}}$. At an $f_{\mathrm{w}}$ of $80 \%$, maximum PL enhancement is attained, whose emission intensity is 23 -fold higher than that in pure THF solution. Further increment of the water content, however, leads to a slight decrease in the emission intensity, probably due to the extensive formation of aggregates, which has lowered the effective solute concentration in solution. Particle size analysis demonstrates the formation of nanoparticles with average diameters of 278, 236 and $134 \mathrm{~nm}$, respectively, in 70, 80 and 99\% aqueous mixtures (Fig. S7 $\dagger$ ). Clearly, the PL of P1/2 is induced and enhanced by aggregate formation and it is thus AIE-active.

Similar to TPE, the mechanism for the AIE properties of 4 and $\mathrm{P} 1 / 2$ is proposed to be associated with the restriction of intramolecular rotation (RIR) in the aggregated state. ${ }^{18}$ The phenyl rings in $\mathbf{4}$ are linked to a carbon-carbon double bond and can undergo rotation freely in the solution state. Such active intramolecular rotation will act as a non-radiative pathway for the excitons to decay to the ground state, rendering 4 non-emissive in pure THF solution and aqueous mixtures with a low $f_{\mathrm{w}}$. However, upon aggregate formation, such motion is restricted due to the physical constraint. This blocks the non-radiative relaxation pathway and thus turns on the emission of the luminogen. Since the TPE units in P1/2 are linked together by covalent bonds, their rotation has been partially restricted in nature. This explains why the polymer is somewhat emissive in pure THF solution albeit in a weak intensity. When polymer aggregates form in the presence of a large amount of water, the RIR process is further activated, which shows further increment of the PL intensity.

Intriguingly, model compound $\mathbf{3}$ is found to be AIE-active even though it carries no TPE unit. As shown in Fig. 6, 3 emits no light under UV irradiation when molecularly dissolved in THF and becomes emissive when $90 \%$ of water is added to the THF solution. Further water addition leads to a stronger emission, with the PL intensity at $99 \%$ water content being 29 -fold higher than that in the pure THF solution. The single crystals of $\mathbf{3 b}$ emit bluer and stronger light (quantum yield $\Phi_{\mathrm{F}}=$ $10.83 \%$ ) than the amorphous aggregates in $99 \%$ aqueous solution $\left(\Phi_{\mathrm{F}}=1.23 \%\right)$.

To gain a further insight into its AIE mechanism, the crystals obtained were characterized by single-crystal X-ray crystallography (Fig. 7). The result shows that $\mathbf{3 b}$ adopts a twisted conformation with large torsional angles $\left(65.16^{\circ}\right.$ and $\left.31.60^{\circ}\right)$ in the crystal state. Multiple weak intermolecular interactions,

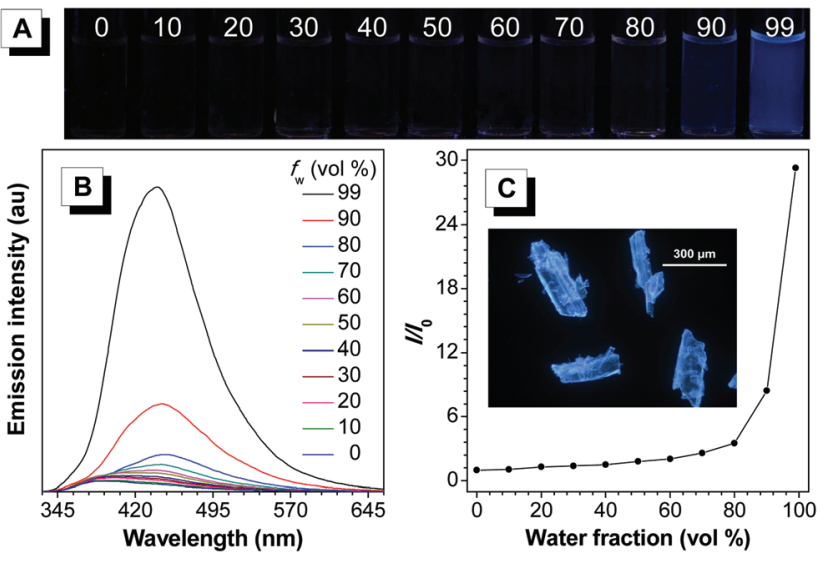

Fig. 6 (A) Photographs of 3 in THF/water mixtures with different water fractions $\left(f_{\mathrm{w}}\right)$ taken under $365 \mathrm{~nm}$ UV irradiation from a hand-held UV lamp. (B) PL spectra of 3 in THF/water mixtures. (C) Plots of the relative $\mathrm{PL}$ intensity $\left(I / I_{0}\right)$ versus the composition of the aqueous mixture of 3 . Solution concentration: $10 \mu \mathrm{M}$; excitation wavelength: $307 \mathrm{~nm}$. Inset: fluorescence image of single crystals of $3 \mathrm{~b}$ taken under a fluorescence microscope. Excitation wavelength: $330-385 \mathrm{~nm}$.
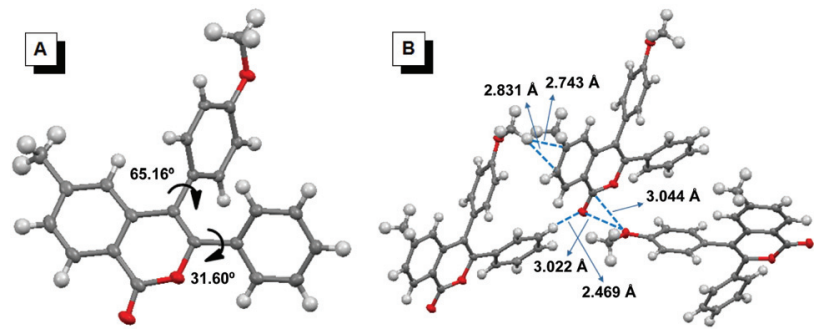

Fig. 7 (A) Molecular structure of model compound 3b (CCDC 1043916) with torsional angles. (B) Illustration of intermolecular interactions between adjacent $\mathbf{3 b}$ molecules.

such as $\mathrm{C}-\mathrm{H} \cdots \mathrm{O}, \mathrm{C}-\mathrm{H} \cdots \mathrm{C}$ and $\mathrm{O} \cdots \mathrm{O}$ interactions, are observed between the adjacent $\mathbf{3 b}$ molecules. Although we failed to obtain the single crystals of $\mathbf{3 a}$, it is supposed that $\mathbf{3 a}$ may adopt a structure similar to $\mathbf{3 b}$. The twisted molecular conformation and the presence of intermolecular interactions hamper the strong $\pi-\pi$ stacking that leads to emission quenching and lock the rotation of the peripheral phenyl rings, thus endowing $\mathbf{3 b}$ with strong solid-state emission. In addition to the RIR mechanism, we have recently proposed that the restriction of intramolecular vibrations (RIV) is another cause for the AIE phenomena. ${ }^{19}$ Some molecules that carry no rotatory moieties but vibrational parts in their structures also show the AIE features. ${ }^{20}$ Inspired by such discovery, we believed that the RIV process might also play a role in the AIE effect of 3 . The vigorous vibration of the isocoumarin ring in 3 will consume the energy of the excited state, leading to emission annihilation in a diluted solution. Such motion, however, is restricted when aggregates are formed, which enables the dye molecules to emit upon photo-excitation. In the crystal state, the RIV process is further activated due to the existence of inter- 
molecular $\mathrm{C}-\mathrm{H} \cdots \mathrm{O}$ and $\mathrm{O} \cdots \mathrm{O}$ interactions (Fig. 7B). Thus, most of the excitons will decay via the radiative pathways, making the crystals emit brighter light than the amorphous aggregates.

\section{Light refraction and photopatterning}

The development of processable polymers with high and tunable refractive indices $(n)$ has drawn wide attention owing to their promising applications in optical waveguides, organic light-emitting diodes, lenses, prisms, memory, image sensors, etc. ${ }^{21}$ The good film-forming ability of $\mathrm{P} \mathbf{1} / \mathbf{2}$ enables us to investigate its light refraction properties. Tough solid films can be readily obtained by spin-coating of its dichloroethane solution onto silicon wafer. As illustrated in Fig. 8, the thin film of P1/2 shows high $n$ values of 1.9697-1.6507 in a wavelength region of $390-890 \mathrm{~nm}$. The $n$ value at $632.8 \mathrm{~nm}$ is 1.6920 , which is much higher than that of conventional optical plastics, such as polyacrylate $(n=1.492)$, polystyrene $(n=1.587)$ and polycarbonate $(n=1.581){ }^{22}$ The high refractivity of $\mathrm{P} 1 / 2$ is reasonable: from its structure, we can find that $\mathbf{P} \mathbf{1} / \mathbf{2}$ possesses many polarized aromatic rings, heteroatoms and ester groups, which are crucial elements for a material to show a high refractive index. ${ }^{23}$ Additionally, the refractivity of $\mathbf{P} \mathbf{1} / \mathbf{2}$ is responsive to UV irradiation. When its film is exposed to UV light, its $n$ values drop progressively upon prolonging the irradiation time (Fig. 8 and Table S3†). The $n$ values decrease to $1.7273-1.6030$ at the same wavelength region at an exposure time of $40 \mathrm{~min}$ and the difference in the $n$ value at $632.8 \mathrm{~nm}$ before and after irradiation is about 0.0746 . The facile UV modulation of the film's refractivity is possibly due to the structural change in the polymer induced by UV light. For a material to be used in optical applications, its chromatic dispersion should be low. The Abbe number $\left(\nu_{\mathrm{D}}\right)$ of a material is used to measure the variation of its $n$ value with wavelength. It is defined as $\left(n_{\mathrm{D}}-1\right) /$ $\left(n_{\mathrm{F}}-n_{\mathrm{C}}\right)$, where $n_{\mathrm{D}}, n_{\mathrm{F}}$ and $n_{\mathrm{C}}$ are the $n$ values at wavelengths of the Fraunhofer D, F and $\mathrm{C}$ spectral lines of 589.2, 486.1 and $656.3 \mathrm{~nm}$, respectively. ${ }^{8 c}$ The chromatic dispersion $(D)$ is the reciprocal of the corresponding $\nu_{\mathrm{D}}$. As summarized in Table S3, $\uparrow$ the $\nu_{\mathrm{D}}$ and $D$ values of $\mathbf{P} \mathbf{1} / \mathbf{2}$ under different irradiation times $(0-40 \mathrm{~min})$ are in the range of 7.7333-17.9358 and 0.1293-0.0558, respectively. The good optical transparency, high and tunable light refraction together

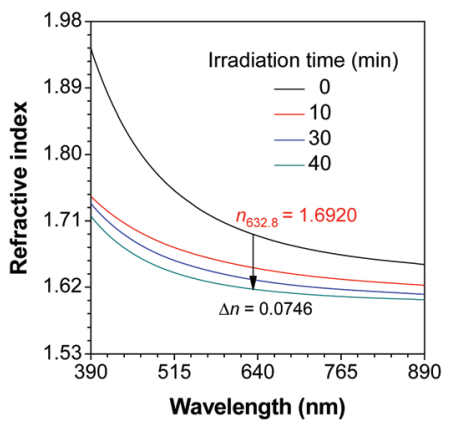

Fig. 8 Wavelength dependence of the refractive index of a thin film of $\mathrm{P} 1 / 2$ on the UV irradiation time.

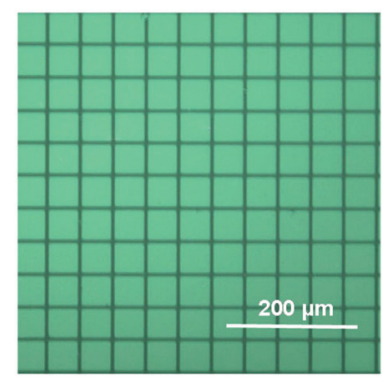

Fig. 9 Two-dimensional fluorescence photopattern generated by photo-oxidation of P1/2. The photograph was taken under $330-385 \mathrm{~nm}$ UV illumination.

with the pretty low optical aberration allow the polymer to serve as a potential coating material in photonic devices. ${ }^{16}$

Considering the high photosensitivity, good film-forming ability and efficient solid-state emission of $\mathrm{P} \mathbf{1} / \mathbf{2}$, we anticipated that the polymer can be applied as an excellent luminescent material as well. Indeed, by irradiating a uniform thin film of P1/2 by UV light through a copper mask under air at room temperature for $20 \mathrm{~min}$, a two-dimensional fluorescent photopattern with unambiguous edges was observed under a fluorescence microscope (Fig. 9). The exposed regions (gridlines) of the film may undergo a strong photo-oxidative bleaching process upon UV illumination in air, and are thus weakly emissive, while the unexposed regions (squares) remain green emissive. The generation of such a fluorescent pattern by a photolithography technique is of great significance in terms of opto-electronic applications. ${ }^{24}$

\section{Conclusions}

In summary, we developed a straightforward and waste-free polymerization route to functional isocoumarin-containing polymers. Unlike some internal alkyne-based polymerization routes with low efficiency, the oxidative polycoupling of aryl diacid $\mathbf{1}$ and internal diyne $\mathbf{2}$ proceeds efficiently in DMF in air in the presence of $\left[\mathrm{Cp}^{*} \mathrm{RhCl}_{2}\right]_{2}$ and a catalytic amount of $\mathrm{Cu}(\mathrm{OAc})_{2} \cdot \mathrm{H}_{2} \mathrm{O}$ at $120{ }^{\circ} \mathrm{C}$ for $24 \mathrm{~h}$, generating a polymer with a high molecular weight in a high yield. The polymer structure was confirmed by comparison of the IR and NMR spectra of P1/2 with those of monomers and model compounds. Notably, an isocoumarin framework forms in situ during the polymerization from readily accessible and inexpensive starting materials. The resulting polymer possesses good thermal stability, optical transparency and film-forming ability. Its thin film exhibits high and tunable refractive indices and is photopatternable. The presence of TPE units in the polymer structure has endowed P1/2 with strong solid-state emission. Given the readily available monomers, simple procedures and advanced properties of the resulting polymer, this oxidative polycoupling reaction can be used as an efficient tool for the construction of fluorescent materials with isocoumarin functionalities for various applications. 


\section{Experimental section}

\section{Materials and instrumentation}

THF was distilled from sodium benzophenone ketyl under nitrogen immediately before use. All the chemicals and other reagents were purchased from Aldrich and used as commercially received without further purification.

Weight-average molecular weight $\left(M_{\mathrm{w}}\right)$ and polydispersity index $\left(M_{\mathrm{w}} / M_{\mathrm{n}}\right)$ of the polymers were estimated on a Waters gel permeation chromatography (GPC) system using THF as an eluent. The details of the experimental setup can be found in our previous publication. ${ }^{25}$ IR spectra were recorded on a PerkinElmer 16 PC FTIR spectrophotometer. All the ${ }^{1} \mathrm{H}$ and ${ }^{13} \mathrm{C}$ NMR spectra were recorded on a Bruker AV 400 spectrometer in deuterated dichloromethane $\left(\mathrm{CD}_{2} \mathrm{Cl}_{2}\right)$ using tetramethylsilane $(\delta=0)$ as an internal reference, except for monomer 1, which was recorded in deuterated dimethylsulfoxide. High-resolution mass spectra (HRMS) were recorded on a GCT premier CAB048 mass spectrometer operating in MALDI-TOF mode. The PL spectra were recorded on a PerkinElmer LS 55 spectrophotometer. UV spectra were recorded on a Milton Ray Spectronic 3000 Array spectrophotometer. TGA was carried on a TA TGA Q5000 under nitrogen at a heating rate of $10^{\circ} \mathrm{C} \mathrm{min}^{-1}$. The thermal transitions were investigated by DSC using a TA Instruments DSC Q1000 at a heating rate of $10{ }^{\circ} \mathrm{C} \mathrm{min}^{-1}$. The particle sizes of the polymer aggregates were measured using a Brookhaven Zeta potential analyzer. The refractive indices of the polymer films were determined using an Alpha-SE Woollam ellipsometer. Photo-oxidation of the polymer film was carried out in air at room temperature using $365 \mathrm{~nm}$ light from a Spectroline ENF-280C/F UV lamp (diameter $=5 \mathrm{~cm}$ ) at a distance of $1 \mathrm{~cm}$ as a light source. The intensity of the incident light intensity was $\sim 18.5 \mathrm{~mW} \mathrm{~cm} \mathrm{~cm}^{-2}$. The procedures for film preparation and photopattern generation were similar to those described in our previously published papers. $^{26}$

\section{Polymer synthesis}

All the polymerization reactions were carried out under air, except for Table 1, entries 1-3, which were conducted under a nitrogen atmosphere using the standard Schlenk techniques. The typical experimental procedures for the polymerization of Table 1, entry 2 and entry 4 are given below as examples.

For entry 2: a $10 \mathrm{~mL}$ Schlenk tube equipped with a magnetic stirrer was charged with $1(0.2 \mathrm{mmol}), 2(0.2 \mathrm{mmol})$, $\left[\mathrm{Cp}^{*} \mathrm{RhCl}_{2}\right]_{2}(0.016 \mathrm{mmol})$ and $\mathrm{Cu}(\mathrm{OAc})_{2} \cdot \mathrm{H}_{2} \mathrm{O}(0.4 \mathrm{mmol})$. The tube was evacuated under vacuum and flushed with dry nitrogen for three times. Then $4 \mathrm{~mL} o$-xylene was injected under nitrogen. The reaction mixture was stirred under a nitrogen atmosphere in an oil bath at $120{ }^{\circ} \mathrm{C}$ for $24 \mathrm{~h}$. Afterward, the reaction was stopped and cooled to room temperature. To remove the catalytic species, especially the copper salt, the resulting mixture was dissolved in a THF/dichloromethane/ chloroform mixture and centrifuged for several times until the supernatant liquid was colourless. Then the solution was concentrated under reduced pressure and added dropwise to
$150 \mathrm{~mL}$ of the chloroform/hexane mixture $(1: 10 \mathrm{v} / \mathrm{v})$ through a cotton filter under vigorous stirring to precipitate the polymer and meanwhile remove, if any, insoluble substances and catalytic species. The precipitates were filtered and washed with hexane and dried in a vacuum at room temperature to a constant weight.

For entry 4: into a $10 \mathrm{~mL}$ Schlenk tube equipped with a magnetic stirrer were added 1 (0.2 mmol), 2 (0.2 mmol), $\left[\mathrm{Cp}^{*} \mathrm{RhCl}_{2}\right]_{2}(0.004 \mathrm{mmol})$ and $\mathrm{Cu}(\mathrm{OAc})_{2} \cdot \mathrm{H}_{2} \mathrm{O}(0.02 \mathrm{mmol})$. Then $2 \mathrm{~mL}$ of dry DMF was added. The resulting solution was stirred for $24 \mathrm{~h}$ at $120{ }^{\circ} \mathrm{C}$ under air. After cooling to room temperature, the reaction mixture was added dropwise into $150 \mathrm{~mL}$ of the chloroform/hexane mixture $(1: 10 \mathrm{v} / \mathrm{v})$ via a cotton filter under stirring to precipitate the polymer. The precipitates were then filtered and washed with hexane and dried under vacuum at room temperature to a constant weight.

P1/2. Light yellow solid; yield $88.1 \%$ (Table 3, entry 2 ). $M_{\mathrm{w}}$ $26300 ; M_{\mathrm{w}} / M_{\mathrm{n}} 2.95$ (GPC, polystyrene calibration). IR (KBr), $\nu$ $\left(\mathrm{cm}^{-1}\right): 3055,3024,2938,2863,1732,1603,1511,1478,1285$, 1244, 1176. ${ }^{1} \mathrm{H}$ NMR (400 $\mathrm{MHz}, \mathrm{CD}_{2} \mathrm{Cl}_{2}$ ), $\delta$ (ppm): 8.10, 8.08, 7.19, 7.08, 6.97, 6.88, 6.72, 6.66, 6.54, 6.36, 3.88, 3.70, 1.73, 1.59, 1.49. ${ }^{13} \mathrm{C}$ NMR (100 $\left.\mathrm{MHz}, \mathrm{CD}_{2} \mathrm{Cl}_{2}\right), \delta$ (ppm): 162.16, 159.91, 159.02, 151.32, 149.89, 142.44, 142.18, 138.34, 134.45, 133.79, 132.59-131.00, 129.57-127.75, 126.89, 125.63, 119.10, $118.81,116.80,116.02,115.10,114.03,112.84,68.23,29.53$, 26.21 .

\section{Model reaction}

To support the structural characterization of P1/2 obtained under a nitrogen atmosphere, model compound $\mathbf{3}$ was first prepared by the oxidative coupling of $p$-toluic acid $\mathbf{5}$ $(2.0 \mathrm{mmol})$ and methoxyl-substituted internal alkyne 6 $(2.4 \mathrm{mmol})$. The reaction was carried out in $o$-xylene $(10 \mathrm{~mL})$ under nitrogen at $120{ }^{\circ} \mathrm{C}$ for $8 \mathrm{~h}$ in the presence of $\left[\mathrm{Cp}^{*} \mathrm{RhCl}_{2}\right]_{2}(0.01 \mathrm{mmol})$ and $\mathrm{Cu}(\mathrm{OAc})_{2} \cdot \mathrm{H}_{2} \mathrm{O}(4.0 \mathrm{mmol})$, using a similar experimental procedure for preparing P1/2 (Table 1, entries 1-3). After cooling to room temperature, the crude product was purified by silica-gel column chromatography using the hexane/ethyl acetate mixture (98:2 v/v) as eluent. A mixture of $\mathbf{3 a}$ and $\mathbf{3} \mathbf{b}$ was collected as a light yellow solid. Yield: 96.1\%. IR (KBr), $\nu$ ( $\left.\mathrm{cm}^{-1}\right): 3034,3004,2969,2931,2836$, 1729, 1608, 1511, 1484, 1294, 1248, 1177. ${ }^{1} \mathrm{H}$ NMR $(400 \mathrm{MHz}$, $\mathrm{CD}_{2} \mathrm{Cl}_{2}$ ), $\delta$ (ppm): 8.22 (dd, 1H), 7.49-7.13 (m, 8H), 7.04-6.91 (m, 2H), 6.76-6.69 (m, 1H), 3.80 (d, 3H), 2.37 (d, 3H). ${ }^{13} \mathrm{C}$ NMR (100 MHz, $\mathrm{CD}_{2} \mathrm{Cl}_{2}$ ), $\delta$ (ppm): 162.45, 162.39, 160.42, 159.88, $151.45,151.39,146.24,146.21,139.63,139.51,135.26,133.95$, $132.79,131.76,131.03,129.78,129.61,129.53,129.41,129.11$, 128.33 , 128.26, 126.77, 126.05, 125.81, 125.51, 118.53, 118.28, $116.94,116.26,114.79,113.65,55.65,55.59,22.31$. HRMS (MALDI-TOF): $\mathrm{m} / \mathrm{z} 342.1243\left(\mathrm{M}^{+}\right.$, calcd 342.1256$)$. Crystallographic data for $\mathbf{3} \mathbf{b}$ has been deposited at the Cambridge Crystallographic Data Centre with a supplementary publication no. CCDC 1043916.

To support the structural characterization of $\mathrm{P} \mathbf{1} / \mathbf{2}$ obtained under aerobic conditions, model compound $\mathbf{4}$ was synthesized by the dehydrogenative coupling of TPE-containing mono- 
carboxylic acid $7(0.5 \mathrm{mmol})$ with $6(0.6 \mathrm{mmol})$. Compound 7 was synthesized according to our previous literature. ${ }^{27}$ This model reaction was carried out in dry DMF $(2.5 \mathrm{~mL})$ under air at $120{ }^{\circ} \mathrm{C}$ for $6 \mathrm{~h}$ in the presence of $\left[\mathrm{Cp}^{*} \mathrm{RhCl}_{2}\right]_{2}(0.005 \mathrm{mmol})$ and $\mathrm{Cu}(\mathrm{OAc})_{2} \cdot \mathrm{H}_{2} \mathrm{O}(0.025 \mathrm{mmol})$. After cooling to room temperature, the crude product was purified by silica-gel column chromatography using the hexane/ethyl acetate mixture $(98: 2$ $\mathrm{v} / \mathrm{v})$ as the eluent. It is hard to separate $\mathbf{4 a}$ and $\mathbf{4 b}$ by column chromatography due to their similar physical properties. Thus, only a mixture of $\mathbf{4 a}$ and $\mathbf{4 b}$ was obtained as a light yellow solid. Yield: $60.1 \%$. IR (KBr), $\nu\left(\mathrm{cm}^{-1}\right): 3054,3021,2927,2838$, $1732,1605,1512,1490,1443,1287,1255,1179 .{ }^{1} \mathrm{H}$ NMR (400 MHz, $\left.\mathrm{CD}_{2} \mathrm{Cl}_{2}\right), \delta(\mathrm{ppm}): 8.12(\mathrm{dd}, 1 \mathrm{H}), 7.34-7.04(\mathrm{~m}, 15 \mathrm{H})$, 7.04-6.88 (m, 7H), 6.75 (dd, 2H), $6.66(\mathrm{dd}, 2 \mathrm{H}), 3.76(\mathrm{~d}, 3 \mathrm{H})$. ${ }^{13} \mathrm{C}$ NMR $\left(100 \mathrm{MHz}, \mathrm{CD}_{2} \mathrm{Cl}_{2}\right), \delta(\mathrm{ppm}): 162.29,162.22,160.36$, 159.54, 151.24, 150.71, 143.54, 143.39, 143.44, 143.09, 140.19, $138.54, \quad 138.46,134.57,133.85,132.68,131.66-131.03$, 129.59-127.97, 127.31, 127.21, 126.14, 125.94, 118.77, 118.50, 116.87, 116.21, 114.57, 113.57, 55.58. HRMS (MALDI-TOF): $\mathrm{m} / \mathrm{z}$ 582.2209 $\left(\mathrm{M}^{+}\right.$, calcd 582.2195).

\section{Acknowledgements}

This work has been partially supported by the National Basic Research Program of China (973 Program; 2013CB834701 and 2013CB834702), the University Grants Committee of Hong Kong (AoE/P-03/08), the National Science Foundation of China (21490570 and 21490574), the Research Grants Council of Hong Kong (604913, 16305014 and 16303815), and the Innovation and Technology Commission (ITC-CNERC14S01). B. Z. T. thanks the support of the Guangdong Innovative Research Team Program (201101C0105067115).

\section{References}

1 (a) J. Z. Liu, J. W. Y. Lam and B. Z. Tang, Chem. Rev., 2009, 109, 5799; (b) W. B. Wu, R. L. Tang, Q. Q. Li and Z. Li, Chem. Soc. Rev., 2015, 44, 3997; (c) J. W. Y. Lam and B. Z. Tang, Acc. Chem. Res., 2005, 38, 745; (d) A. J. Qin, J. W. Y. Lam and B. Z. Tang, Chem. Soc. Rev., 2010, 39, 2522.

2 Y. Tokoro, H. Sato and S. Fukuzawa, ACS Macro Lett., 2015, 4, 689.

3 B. Pourabas and A. Banihashemi, Polym. Int., 2002, 51, 1086.

4 J. Gruber, R. W. C. Li, A. M. L. Silva and J. R. Matos, Polym. J., 1997, 29, 718.

5 Y. F. Li, Acc. Chem. Res., 2012, 45, 723.

6 N. H. Yin and L. H. Feng, Dyes Pigm., 2015, 117, 116.

7 Y. J. Liu, Z. Zhao, J. W. Y. Lam, Y. Y. Zhao, Y. C. Chen, Y. Liu and B. Z. Tang, Macromolecules, 2015, 48, 4241.

8 (a) J. Ling, M. Z. Rong and M. Q. Zhang, J. Mater. Chem., 2011, 21, 18373; (b) H. Q. Deng, Z. K. He, J. W. Y. Lam and B. Z. Tang, Polym. Chem., 2015, 6, 8297; (c) Y. J. Liu, J. W. Y. Lam and B. Z. Tang, Natl. Sci. Rev., 2015, 2, 493.
9 (a) B. M. Kobilka, A. V. Dubrovskiy, M. D. Ewan, A. L. Tomlinson, R. C. Larock, S. Chaudhary and M. Jeffries-El, Chem. Commun., 2012, 48, 8919; (b) M. V. Biyani, C. Weder and E. J. Foster, Polym. Chem., 2014, 5, 5501; (c) K. Wang, X. Y. Zhang, X. Q. Zhang, B. Yang, Z. Li, Q. S. Zhang, Z. F. Huang and Y. Wei, Polym. Chem., 2015, 6, 1360.

10 (a) M. L. Keshtov, G. D. Sharma, S. A. Kuklin, I. E. Ostapov, D. Y. Godovsky, A. R. Khokhlov and F. C. Chen, Polymer, 2015, 65, 193; (b) S. Gunes, H. Neugebauer and N. S. Sariciftci, Chem. Rev., 2007, 107, 1324.

11 I. Osaka, T. Abe, M. Shimawaki, T. Koganezawa and K. Takimiya, ACS Macro Lett., 2012, 1, 437.

12 (a) K. Sierolawski, K. Slepokura, T. Lis, M. Bogucka, J. Lutomska and A. Kraszewski, Acta Crystallogr., Sect. C: Cryst. Struct. Commun., 2006, 62, O405; (b) V. Rukachaisirikul, A. Rodglin, Y. Sukpondma, S. Phongpaichit, J. Buatong and J. Sakayaroj, J. Nat. Prod., 2012, 75, 853.

13 (a) R. C. Larock and T. R. Hightower, J. Org. Chem., 1993, 58, 5298; (b) K. Cherry, J. L. Parrain, J. Thibonnet, A. Duchene and M. Abarbri, J. Org. Chem., 2005, 70, 6669; (c) M. Peuchmaur, V. Lisowski, C. Gandreuil, L. T. Maillard, J. Martinez and J. F. Hernandez, J. Org. Chem., 2009, 74, 4158; (d) W. J. Yoo, T. V. Q. Nguyen and S. Kobayashi, Angew. Chem., Int. Ed., 2014, 53, 10213.

14 (a) K. Ueura, T. Satoh and M. Miura, J. Org. Chem., 2007, 72, 5362; (b) K. Ueura, T. Satoh and M. Miura, Org. Lett., 2007, 9, 1407.

15 (a) M. Zhang, G. X. Feng, Z. G. Song, Y. P. Zhou, H. Y. Chao, D. Q. Yuan, T. T. Y. Tan, Z. G. Guo, Z. G. Hu, B. Z. Tang, B. Liu and D. Zhao, J. Am. Chem. Soc., 2014, 136, 7241; (b) N. B. Shustova, B. D. McCarthy and M. Dinca, J. Am. Chem. Soc., 2011, 133, 20126; (c) M. Gao, J. W. Y. Lam, J. Li, C. Y. K. Chan, Y. L. Chen, N. Zhao, T. Y. Han and B. Z. Tang, Polym. Chem., 2013, 4, 1372; (d) M. Gao, J. W. Y. Lam, Y. J. Liu, J. Li and B. Z. Tang, Polym. Chem., 2013, 4, 2841.

16 (a) R. Fermento, D. C. Leitao, J. M. Teixeira, A. M. Pereira, F. Carpinteiro, J. Ventura, J. P. Araujo and J. B. Sousa, J. Non-Cryst. Solids, 2008, 354, 5279; (b) C. K. W. Jim, A. J. Qin, J. W. Y. Lam, M. Haussler, J. Z. Liu, M. M. F. Yuen, J. K. Kim, K. M. Ng and B. Z. Tang, Macromolecules, 2009, 42, 4099; (c) C. Y. K. Chan, J. W. Y. Lam, C. K. W. Jim, H. H. Y. Sung, I. D. Williams and B. Z. Tang, Macromolecules, 2013, 46, 9494.

17 (a) Y. L. Zhang, J. Xia, X. Feng, B. Tong, J. B. Shi, J. G. Zhi, Y. P. Dong and Y. Wei, Sens. Actuators, B, 2012, 161, 587; (b) Z. J. Zhao, J. W. Y. Lam and B. Z. Tang, J. Mater. Chem., 2012, 22, 23726.

18 (a) A. J. Qin, C. K. W. Jim, Y. H. Tang, J. W. Y. Lam, J. Z. Liu, F. Mahtab, P. Gao and B. Z. Tang, J. Phys. Chem. B, 2008, 112, 9281; (b) Y. N. Hong, J. W. Y. Lam and B. Z. Tang, Chem. Commun., 2009, 4332; (c) G. Y. Qing, X. X. Shan, W. R. Chen, Z. Y. Lv, P. Xiong and T. L. Sun, Angew. Chem., Int. Ed., 2014, 53, 2124; (d) T. Han, 
Y. J. Zhang, X. Feng, Z. G. Lin, B. Tong, J. B. Shi, J. G. Zhi and Y. P. Dong, Chem. Commun., 2013, 49, 7049.

19 (a) J. Mei, Y. N. Hong, J. W. Y. Lam, A. J. Qin, Y. H. Tang and B. Z. Tang, Adv. Mater., 2014, 26, 5429; (b) J. Mei, N. L. C. Leung, R. T. K. Kwok, J. W. Y. Lam and B. Z. Tang, Chem. Rev., 2015, 115, 11718.

20 (a) N. L. C. Leung, N. Xie, W. Z. Yuan, Y. Liu, Q. Y. Wu, Q. Peng, Q. Miao, J. W. Y. Lam and B. Z. Tang, Chem. - Eur. J., 2014, 20, 15349; (b) T. Nishiuchi, K. Tanaka, Y. Kuwatani, J. Sung, T. Nishinaga, D. Kim and M. Iyoda, Chem. - Eur. J., 2013, 19, 4110.

21 (a) J. G. Liu and M. Ueda, J. Mater. Chem., 2009, 19, 8907; (b) M. Maheswara, S. H. Oh, J. J. Ju, S. K. Park, S. Park and J. Y. Do, Polym. J., 2010, 42, 249; (c) T. Matsuda, Y. Funae, M. Yoshida, T. Yamamoto and T. Takaya, J. Appl. Polym. Sci., 2000, 76, 45.

22 (a) Y. J. Liu, M. Gao, J. W. Y. Lam, R. R. Hu and B. Z. Tang, Macromolecules, 2014, 47, 4908; (b) J. Brandrup, E. H. Immergut and E. A. Grulke, Polymer handbook, Wiley, New York, Chichester, 4th edn, 2004; (c) J. E. Mark, Polymer data handbook, Oxford University Press, Oxford, New York, 2009.

23 R. R. Hu, N. L. C. Leung and B. Z. Tang, Chem. Soc. Rev., 2014, 43, 4494.

24 (a) M. Campbell, D. N. Sharp, M. T. Harrison, R. G. Denning and A. J. Turberfield, Nature, 2000, 404, 53; (b) Z. A. Li, Z. Q. Jiang, S. H. Ye, C. K. W. Jim, G. Yu, Y. Q. Liu, J. G. Qin, B. Z. Tang and Z. Li, J. Mater. Chem., 2011, 21, 14663.

25 C. Y. K. Chan, N. W. Tseng, J. W. Y. Lam, J. Z. Liu, R. T. K. Kwok and B. Z. Tang, Macromolecules, 2013, 46, 3246.

26 P. Lu, J. W. Y. Lam, J. Z. Liu, C. K. W. Jim, W. Z. Yuan, C. Y. K. Chan, N. Xie, Q. Hu, K. K. L. Cheuk and B. Z. Tang, Macromolecules, 2011, 44, 5977.

27 (a) M. He, R. T. K. Kwok, Z. G. Wang, B. Duan, B. Z. Tang and L. N. Zhang, ACS Appl. Mater. Interfaces, 2014, 6, 9508; (b) Z. G. Song, Y. N. Hong, R. T. K. Kwok, J. W. Y. Lam, B. Liu and B. Z. Tang, J. Mater. Chem. B, 2014, 2, 1717; (c) G. D. Liang, J. W. Y. Lam, W. Qin, J. Li, N. Xie and B. Z. Tang, Chem. Commun., 2014, 50, 1725. 